\title{
Emerging Challenges Faced by Dentists after Covid-19 Pandemic in India
}

\section{Deepthi Sogasu ${ }^{1}$, Jayalakshmi Somasundaram², Smiline Girija AS ${ }^{3}$}

Section: Healthcare

Sci. Journal Impact

Factor: $6.1(2018)$

ICV: 90.90 (2018)

(c) (i) (8)

Copyright@IJCRR
'Saveetha Dental College, Saveetha Institute of Medical and Technical Science, Saveetha University, Chennai 77, India; ${ }^{2}$ Chief Scientist, White Lab - Material Research Center, Saveetha Dental College, Saveetha Institute of Medical and Technical Science, Saveetha University, Chennai- 77, India; ${ }^{3}$ Associate professor, Department of Microbiology, Saveetha Dental College, Saveetha Institute of Medical and Technical Science, Saveetha University, Chennai- 77, India.

\section{ABSTRACT}

Aim: To understand and analyze the various emerging challenges that dentists will face after COVID 19 pandemic in India.

Materials and Methods: Online survey platform - Google forms were used to formulate the survey. Online interfaces like WhatsApp, Gmail, etc. were used to share the survey. The data collected was then analyzed using software like IBM SPSS Statistics 23.

Introduction: The novel coronavirus pandemic is infecting more and more people day after day. This is so, because of the virus' mode of transmission. It can be easily transmitted through air and droplet infection. It can easily spread through aerosols too. The coronavirus is considered as a part of the SARS and MERS CoV family. For the same reasons, speculation remains about the novel virus' transmission through the fecal-oral route. Since it is a highly contagious virus, health care professionals are at an increased risk of infection. Dental professionals especially are required to take more precautions to protect themselves from the aerosols produced. This can be achieved if the dentists reduce aerosol producing procedures and wear proper PPE. This survey study discusses all the future problems faced by dentists after the lockdown is alleviated. The information for this survey was collected using a self-prepared questionnaire which was distributed among general dental practitioners in India. The questions were based on the various problems faced by dentists and how they will cope with the current situation. The responses were recorded and statistically analyzed to obtain the results. From the responses obtained, it can be concluded that the dentists face various problems. The most evident concerns are infection control, aerosols, and adequate PPE.

Results: The results suggest that the primary challenges to be faced by the dentists will be dependent on their geographical location. The most important challenge anticipated by the majority of dentists is the increased use of PPE and aerosol production, in the same order.

Conclusion: There are definitely a lot of changes to be made in dental practice after the COVID-19 pandemic. Understanding the most important ones and prioritizing them is of utmost importance.

Key Words: COVID-19, Virology, Infection control, Dental public health, Dental practice management, Dental education, Aerosol reduction

\section{INTRODUCTION}

The novel coronavirus is a highly infectious virus causing respiratory problems such as pneumonia. The virus is known to have originated from the wet markers in Wuhan, China ${ }^{1}$. The mode of transmission of the virus is via droplets and aerosols ${ }^{2}$. Due to this mechanism of transmission of the virus, dentists are the most prone to infection. The novel COVID 19 is very similar to the SARS CoV and MERS CoV. It is considered a zoonotic disease. The main host is considered as a bat ${ }^{3,4}$ and the intermediate host is considered to be a Pangolin. Once it spreads to humans (mainly due to consumption of uncooked meat of the respective animal), it marks the interspecies cross over. This is followed by a human to human spread of the virus. The main source of spread is from symptomatic patients. It has been found that the spread can also occur for asymptomatic patients ${ }^{5}$. The incubation period of the virus in the body can vary between 5 to 6 days on an average, but extend up to 14 days thus, facilitating the asymptomatic spread of the virus. ${ }^{6,7}$. The treatment of the virus is complicated in patients with pre-existing medical conditions such as diabetes or cardiovascular problems ${ }^{8,9}$. Thus adequate awareness of the same is important among dentists. It is also important

\section{Corresponding Author:}

Jayalakshmi Somasundaram, Chief scientist, White Lab - Material research center, Saveetha Dental College, Saveetha Institute of Medica and Technical Sciences, No.162, PH Road, Chennai-600 077, Tamil Nadu, India; Mobile: +91 9600586858; Email: jayalakshmisomasundaram@saveetha.com

ISSN: 2231-2196 (Print)

Received: 19.07.2020
ISSN: $0975-5241$ (Online)

Revised: 22.08 .2020
Accepted: 14.09 .2020
Published: 20.10 .2020 
that the dentists are aware of and vaccinated for hepatitis B, failing which can make them more prone to infections ${ }^{10}$. Another reason why the treatment of COVID is difficult is due to antibiotic resistance. The three most common mechanisms for mutations in viruses include physical mutagens such as UV and X rays; the natural behavior of the bases that make up the nucleotide such as resonance, and the fallibility of the enzymes. Those viruses which have a high degree of accuracy during copying of the nucleic acids, the mutation rates are lower ${ }^{11}$. This occurs due to the unparented consumption of antibiotics by patients without consultation with a doctor ${ }^{12,13}$. Apart from antibiotics, another commonly used drug is NSAIDs. These chemical drugs can be replaced with natural sources like cloves, garlic, turmeric, and even bey leaves. They are known to have anti-inflammatory properties ${ }^{14}$.

It is known that the coronavirus is abundantly present in the nasopharyngeal areas and the salivary secretions of the infected individual after infection ${ }^{15,16}$. The dental professional may come in contact with infected patients when they come for treatment. During dental treatment, the virus can be aerosolized and gets dispersed into the air; which eventually settles down with time and tends to contaminate various surfaces like switches, various parts of the dental chair, and some of the sterilized instruments. Aerosols are mostly produced in dental practices due to the use of various dental instruments such as high-speed handpieces, ultrasonic scalers, etc ${ }^{17,18}$. It is thus very important to maintain safety precautions to prevent the spread of infection. It is also advised that special care be taken while treating patients with other underlying systemic infections such as UTI or nosocomial infections ${ }^{19,20}$.

Currently, there are no available vaccines for COVID, but steps are taken for the development of vaccines against COVID 19. The vaccines are being meticulously developed using various bioinformatics tools and in silico analysis ${ }^{21,22}$ In favor of the dental professions, the Indian Dental Association (IDA) has provided various guidelines for infection control. IDA persuades the dentists to be proactive in implementing all the necessary changes and preventing the spread of infection ${ }^{23}$. Awareness among dental professionals about guidelines is of utmost importance. The first guideline provided by the IDA is to reduce or minimize the chance of exposure. Dentists are also warned about treating patients with respiratory tract infections. The following few guidelines suggest the use of proper PPE, hand hygiene, cough etiquette, proper waste disposal practices, etc. Similar guidelines have also been given by the American Dental Association (ADA) for the dental professions and after a dental procedure ${ }^{24}$.

A recent study ${ }^{25}$ published stated that countries like Singapore, Taiwan, and Hong Kong which have close links to China quickly adhered to measures to control infections. These measures include: i) the reduction of self-employed arrival of new cases into the community; ii) reduction of any possible transmission from the already infected to the rest of the population; iii) suppress asymptomatic spread through social distancing and staying at home with heightened hygiene measures. In other countries like the UK, the government suggested that general dental practitioners (GDP) continue to treat asymptomatic patients. Most of the GDPs felt that this was very risky. Many refused to treat patients. This was out of fear of getting infected. Another problem faced by the self-employed dental practitioners is the finance involved obtaining enough PPE and disinfectants along with payment of dental assistants. The GDPs felt that the rule given by the UK government was not logical ${ }^{26}$. An article published by a Dean of Dentistry- E Emami states that the current situation has greatly affected dental students and professionals. Now, mostly all the facilities have become online courses. Special communication lines have also been developed such as virtual wellness hubs, technological platforms have also been created to reduce loneliness and also increase accessibility and awareness ${ }^{27}$. Another recent article published in China suggested that hand hygiene is the most crucial for infection control. The author also suggested that only emergency dental cases must be considered for some time. He also stated that it would be preferred to postpone dental treatment by at least one month after the lockdown is relieved ${ }^{28}$.

Previous literature suggests that the main cause of emergency dental treatment is due to pulpal periapical diseases, gingival and periodontal diseases, and oral soft tissue infections ${ }^{29}$. Dental services can enable positive attitudes and constructive changes for the benefits of the patient ${ }^{30}$. This survey is aimed at identifying the future problems that the dental professionals in India are likely to face once the pandemic is brought under control.

\section{MATERIALS AND METHODS}

This study is based on a survey conducted among 205 participants comprising dental practitioners in India with different years of experience in the field. The participants were asked to complete the survey regarding the present concerns and possible future problems they anticipate facing after the lockdown is relieved. The sampling method employed is random sampling. The questions were formed such that they are short, clear, and straightforward. This was done to eliminate any sampling bias. The participants allowed to participate in this survey included general dental practitioners, specialized dental practitioners, postgraduate students, undergraduate interns. All the participants included the study work in India.

The participants were excluded if they work abroad but are Indian by nationality, students doing preclinical work were also excluded from the survey. A self-structured questionnaire consisting of 10 questions were checked for validity by 
three internal experts [within Saveetha Dental College] and three external experts [from outside Saveetha Dental College]. The software used for data collection is Google forms. Various output variables include the different infection control methods, frequencies of various procedures performed by each dentist. The dependent variables in the survey are the geographic location, methods to prevent excess aerosol production, and the uses of PPE. Independent variables are the age, sex of the participant. The results were collected and statistically analyzed using IBM SPSS Statistics 23 to finally obtain the results.

\section{RESULTS AND DISCUSSION}

All the 205 responses obtained for the survey had individualized and unique responses. The first question following the name of the dentist was the number of years of experience in the dental field. To this question, out of the total [ $\mathrm{n}=205], 82$ individuals [40\%] have about 1 year of experience; 62 individuals [32.2\%] have 2 years of experience; 21 individuals [10.2\%] have 3 years of experience; 15 individuals [7.3\%] have 10 years of experience; 10 individuals [4.9\%] have 4 years of experience; 3 individuals [1.5\%] have 9 years of experience; 2 individuals [1\%] have 7 years of experience and 1 individual $[0.5 \%]$ has 8 years of experience. These results suggest that most of the respondents are new to the dental field with the majority having 1 year of work experience. [Graph 1].

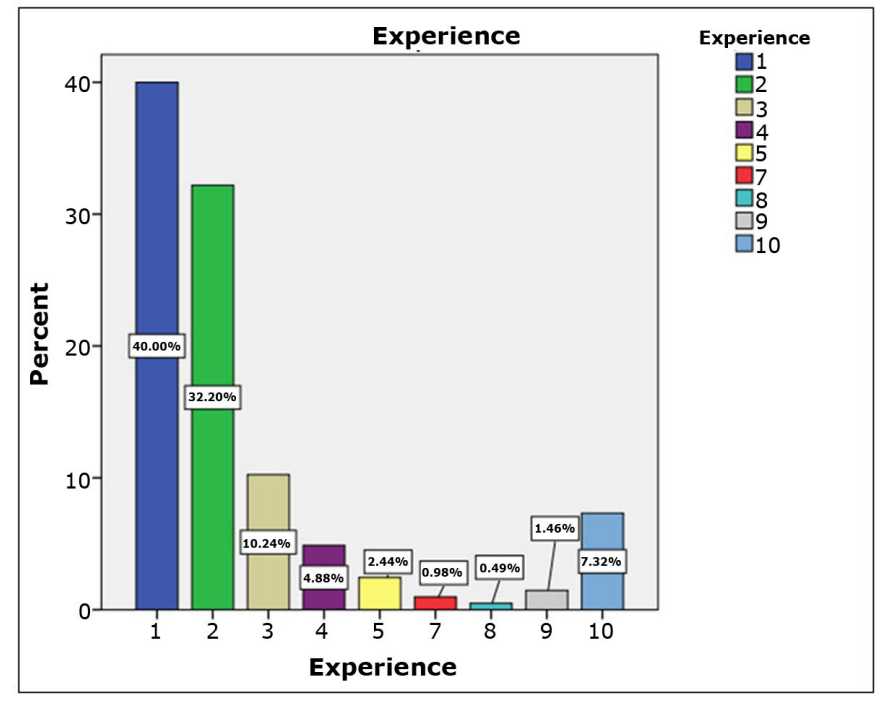

Graph 1: Bar chart representing the percentage distribution (\%) for the responses to the question "Years of work experience". The majority of the respondents reported having $<5$ years of experience (87.3\%). $12.4 \%$ of the respondents have 5 and more years of dental work experience.
The following question was whether the dentist owns his/her clinic. To this, 175 respondents [85.4\%] responded "No" and 30 respondents [14.6\%] answered "Yes". These results are supported by a study stating that the reason for many dentists not having their clinics in India is due to the financial crisis they face, lack of support from the government, and the already saturated market ${ }^{31}$. [Graph 2].

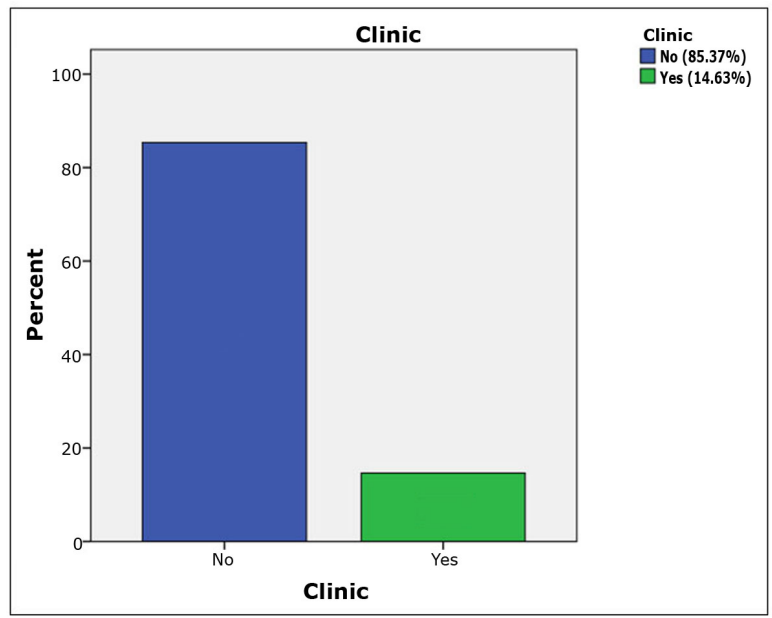

Graph 2: Bar graph representing the percentage distribution (\%) for the responses to the question "Do you own your own clinic". The majority of the respondents reported that they don't own a clinic $(85.4 \%)$ [blue]. Only $(14.6 \%)$ of the respondents reported that they own a clinic [green].

The next question was about which state the dentist practices. 119 participants [58\%] work in Tamilnadu, 65 respondents [31.7\%] were from Karnataka, and 7 participants [3.5\%] each from Kerala and Maharashtra. [Graph 3].

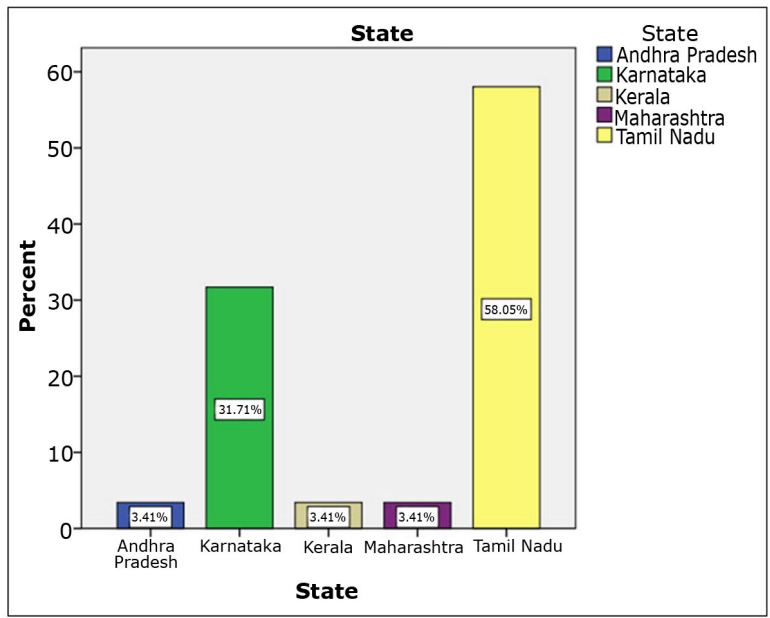

Graph 3: Bar graph representing the percentage distribution (\%) for responses to the question "Your workplace is situated in which state of India?". The majority of the respondents reported that they work in Tamil Nadu (58.1\%) [yellow]. 31.7\% of the respondents reported working from Karnataka [green]. Only $(3.4 \%)$ of the respondents reported that they work in Kerala [brown], Maharashtra [purple], and Andhra Pradesh [blue]. 
When asked about the problems currently faced by dentists, 189 individuals [92.2\%] answered "all of the above"; which included aerosol production, infection control, and lack of PPE. 9 participants responded "infection control", 1 person responded for lack of PPE, and 6 people [2.9\%] responded for "aerosol production". Similar articles after the SARS CoV outbreak provided guidelines which concluded that the major guidelines are infection control and aerosol reduction in a dental setting. Infection control involves following all the guidelines listed by WHO, IDA, etc ${ }^{32,33}$. [Graph 4]

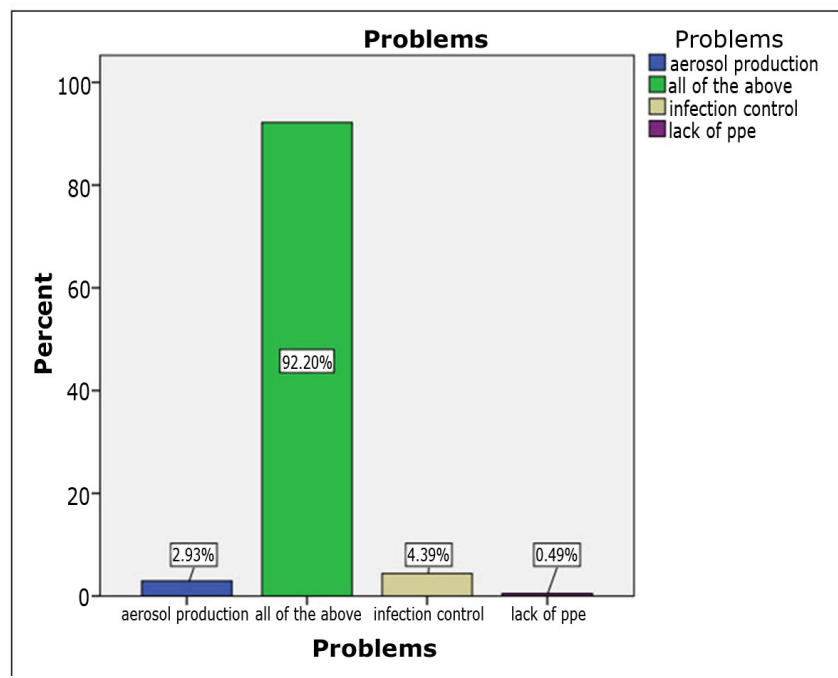

Graph 4: Bar graph representing the percentage distribution (\%) for the responses to the question "What are the problems you think you are going to face once you resume practice?". The majority of the respondents reported with the answer all of the above (92.2\%) [green]. $4.3 \%$ of the respondents feel that infection control is a major problem [brown]. $2.9 \%$ of the respondents reported that the main problem is aerosol production [blue].

The next question in the survey was regarding the difficulty in the collection of personal protective equipment [PPE]. 98 people [47.8\%] responded that it is 'very difficult' to obtain PPE, 95 people [46.3\%] responded that it is 'difficult' to obtain PPE, whereas 8 people [3.9\%] responded that it is 'easy' to obtain PPE and 4 people [2\%] felt that it is 'very easy' to obtain PPE. Recent articles suggest that according to the government there is no need for any worry about the stock of PPE but there must be rational use of the available PPE ${ }^{34}$. But the results obtained in this survey suggest the opposite and contraindicates the government's assurance. This can be as a result of which state the dentist practices in. There may be a possibility that few states like Maharashtra and Kerala are getting better stocks of PPE ${ }^{35}$ [Graph 5].

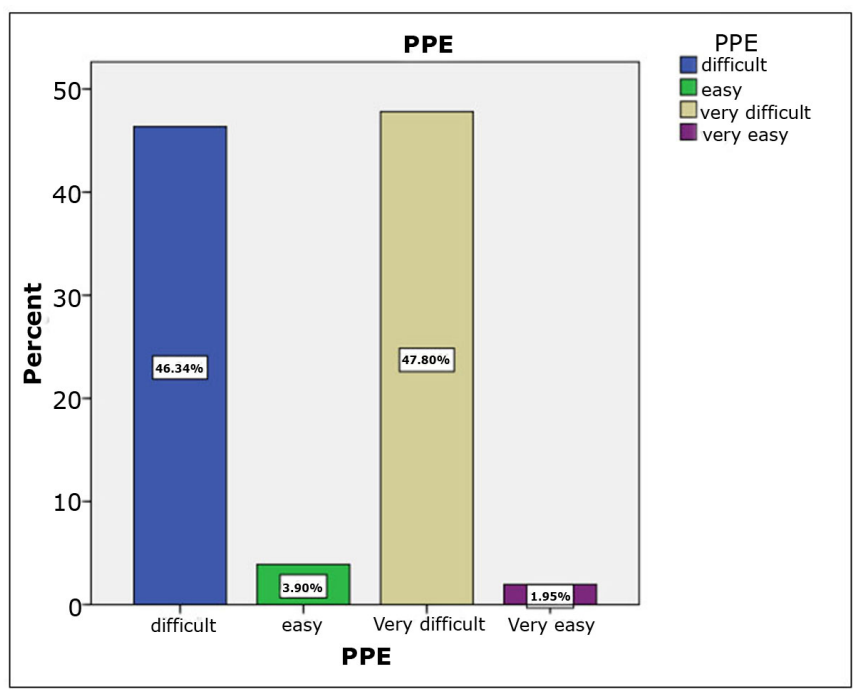

Graph 5: Bar graph representing the percentage distribution (\%) for the responses to the question "How difficult has it been to stock up on PPE?". The majority of the respondents reported that it is very difficult to obtain PPE (47.8\%) [brown]. It is closely followed by $46.3 \%$ of the respondents reporting that it is difficult to obtain PPE [blue]. 3.9\% of the respondents feel that it is easy to obtain PPE [green]. Only $2.0 \%$ of the respondents reported that it is very easy to obtain PPE [purple].

The next question is about the anticipated changes which the dentists will make to cope up with the guidelines for the pandemic. With the nature of the question being an open one, the answers received were subjective and diverse. Each practitioner answered individually. The resulting frequency will not be equal to $100 \%$. The most common response was increased use of appropriate PPE, effective infection control protocols, and aerosol production in decreasing order of frequencies. Other responses included disinfection after the procedure, use of fumigating agents, only attending to emergency procedures, the use of sterilizing agents, hand sanitizers, social distancing among patients in the waiting area.

From the previous studies published after the SARS outbreak, it was stated that hospital infection control involved proper education of infection management among employees. It also involved the construction of hospitals in such a way that they can deal with emergency cases such as outbreaks like SARS that allows them to be prepared for such public health events ${ }^{36}$. Currently, the dental community is reflecting on the SARS outbreak and their methods for infection control, so they can reinforce the same for now ${ }^{37}$. Recent studies have also suggested that the use of an antibacterial mouth rinse correctly by the patient before the dental procedure can significantly reduce the number of infected aerosols produced during the spread. It has been suggested that chlorhexidine mouthwashes work well as an antimicrobial mouthwash before the dental procedure for adults ${ }^{38,39}$. Orange peel essential oil has been recommended as an alter- 
native to $\mathrm{CHX}$ among pediatric patients. ${ }^{40}$. The endodontists are also advised to use chlorhexidine as intracanal medicament during procedures ${ }^{41}$. Such measures can control and reduce the risk of endogenous infection ${ }^{42}$. It is known that in-office radiography can sometimes stimulate coughing, thus, it is advised to avoid as much as possible ${ }^{43}$. Patient management is also very important. Only the emergency cases must be considered as of now. Some trauma guidelines have also been published which suggests the priority of patients. So, patients with avulsed or fractured teeth must be considered as emergency patients and be treated immediately ${ }^{44}$. [Table 1].

Table 1: Table representing the percentage distribution of the responses to the question "What are the future changes to practice guidelines in workspace to prevent spread of infection". The responses acquired were subjective. Among all the responses, the majority of the respondents reported that the most common change to be implemented is the increased use of PPE ( $n=72)$, implementing efficient infection control protocol $(n=70)$, aerosol reduction $(n=49)$, disinfection $(n=36)$, fumigation $(n=31)$, and social distancing $(n=29)$.

\begin{tabular}{lc} 
Changes to be made in the future & Frequency \\
Increased use of PPE & 72 \\
Aerosol reduction & 49 \\
Infection Control Protocol & 70 \\
Extensive use of Hand sanitizer & 1 \\
Emergency treatment only & 3 \\
Social distancing & 29 \\
Fogging & 14 \\
Disinfection & 36 \\
Fumigation & 31 \\
Limiting patients & 7 \\
Patient testing kits & 12 \\
\hline
\end{tabular}

The next question in the survey is regarding the time duration until which these changes must be maintained to curb the spread of infection. 105 respondents [51.2\%] felt that 1 year time period is sufficient; 40 respondents [19.5\%] felt that 1.5 years time period is sufficient; 29 respondents [14.1\%] suggested that 6 months is sufficient and 21 respondents [10.2\%] felt that 8 months will be enough time. 8 respondents [3.9\%] felt that the changes must be maintained until the disease is under control and 2 people [1\%] felt that permanent change is the solution. According to the operational guidance for maintaining essential health services dur- ing an outbreak by WHO 2020, it was stated that the interim guidelines and changes must be followed and maintained until necessary ${ }^{45}$ thus, contradicting the results in this survey. Even Though the majority feel that a 1-1.5 years time period is enough, it is difficult to predict the patterns of spread of the virus and the time it takes to curb the spread of infection. Thus, the changes must be maintained until necessary or for increased safety, even permanently. [Graph 6]

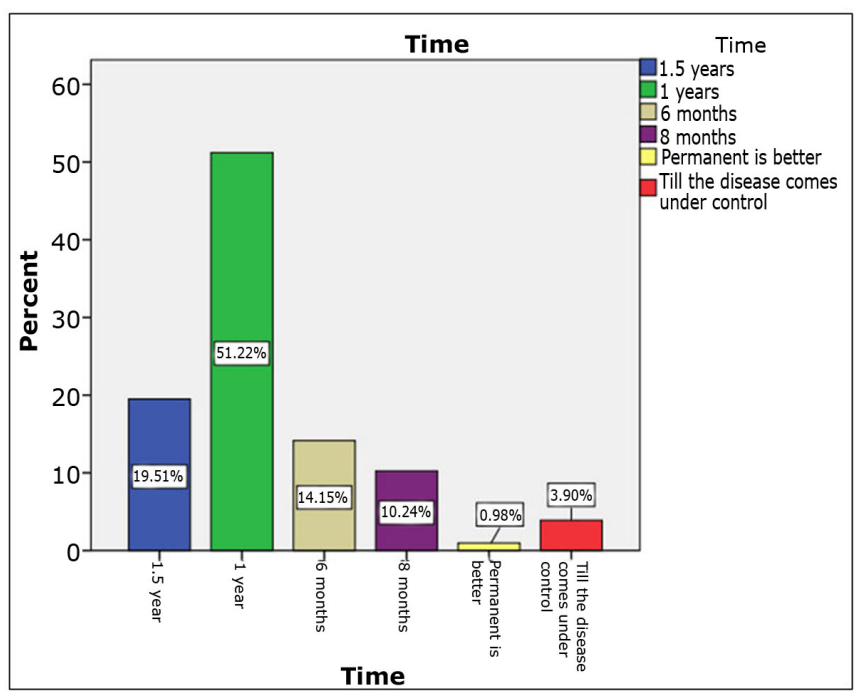

Graph 6: Bar graph representing the percentage distribution (\%) for the responses to the question "For how long will the changes in your workplace be maintained?". Majority of the respondents reported that the changes must be maintained for 1 year $51.3 \%$ [green]. $19.5 \%$ of the respondents feel that the changes ought to be maintained for 1.5 years[blue]. While $14.1 \%$ of the respondents felt that maintaining these changes for 6 months is enough time[brown]. $10.2 \%$ of the respondents felt that the changes in clinics must be maintained for at least 8 months[purple]. A minor percentage of the respondents $-3.9 \%$ felt that strict maintenance of the changes must be done until the disease is under control[red]. Only $1.0 \%$ of the respondents reported that it is necessary to maintain the changes permanently[yellow].

The next question was about how COVID 19 has affected the dental profession. 157 participants [76.6\%] feel that it is a 'huge disadvantage', whereas 44 people [21.5\%] felt that the situation is manageable and can be restored to normal. 4 people [2\%] felt no evident change or impact. The ADA also suggests that there is a significant negative impact on dentistry and dental professionals. This affects the pay status of the employees, the extra expenditure on good quality PPE and N95 masks, and the fear of transmission of the disease ${ }^{46}$. [Graph 7] 


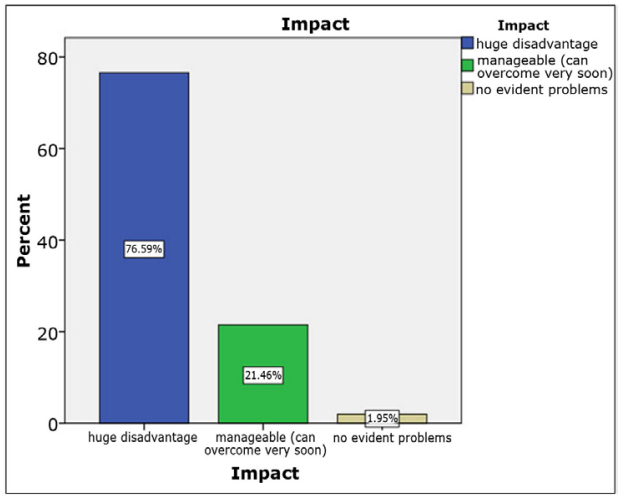

Graph 7: Bar graph representing the percentage distribution (\%) for the responses to the question "What is your understanding of the impact of n-CoV 19 on the dental profession". The majority of the respondents reported that $n-\mathrm{CoV}$ is a huge disadvantage to dentistry $76.5 \%$ [blue]. $21.5 \%$ of the respondents feel that $n-\mathrm{CoV}$ has had an impact on dentistry, but it can be overcome and managed with time [green]. Only $2.0 \%$ of the respondents reported that $\mathrm{n}-\mathrm{CoV}$ doesn't cause any evident problems in dentistry [brown].

The last question of the survey was about whether the testing of patients is necessary before dental procedures. 194 respondents [94.6] agreed that it is necessary for testing. 8 respondents [3.9\%] felt that it is not necessary for testing the patients and 3 people; [1.5\%] felt that the testing may be needed only in some cases and depends on its availability [testing kits]. Some dental professionals feel that patient testing can jeopardize the dental profession. It is an extra expenditure. They feel that just proper PPE and infection control protocol is enough before any dental procedure, especially for asymptomatic patients ${ }^{47}$. [Graph 8]

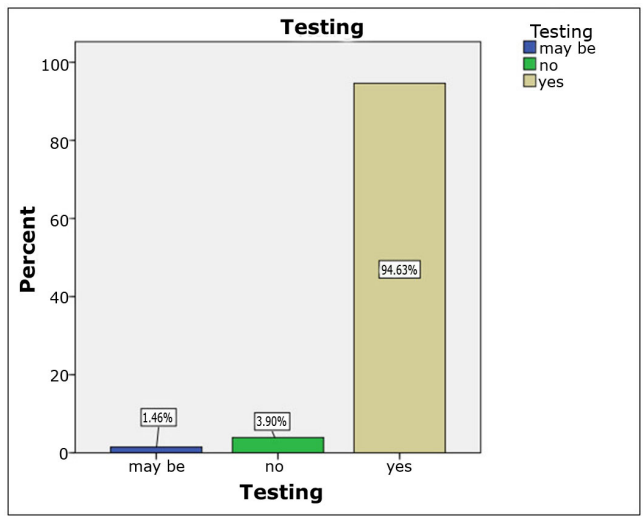

Graph 8: Bar graph representing the percentage distribution (\%) for the responses to the question "Is covid testing a must for every patient undergoing ANY dental treatment? [Scaling to surgery]". The majority of the respondents reported that they will test all the patients before any dental (94.6\%) [brown]. $3.9 \%$ of the respondents feel that it is not necessary to check the patients before dental procedures [green]. Only (1.5\%) of the respondents reported that they may or may not test the patients depending on the availability of the tests [blue].

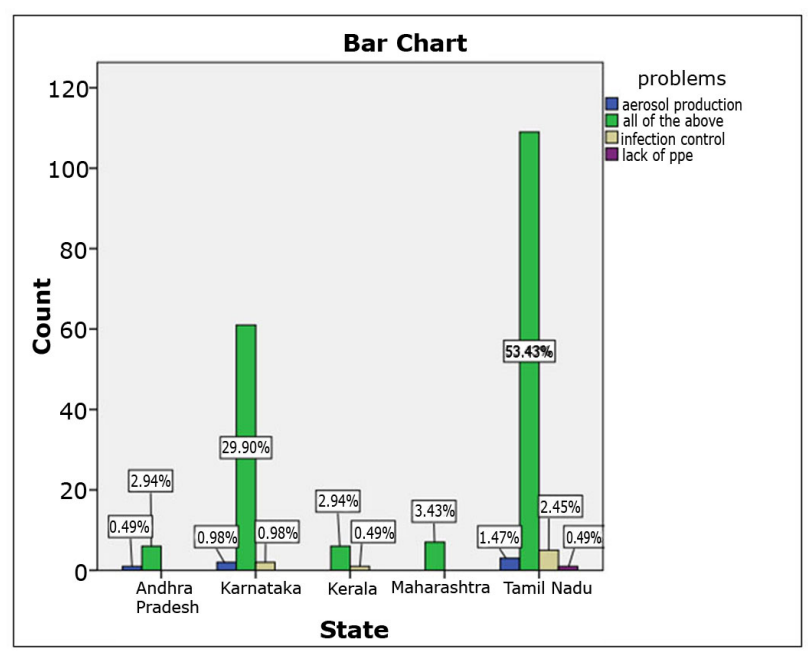

Graph 9: Bar graph representing the comparison between which state the professionals work in and the current problems faced by them. $\mathrm{X}$-axis represents the states and $\mathrm{Y}$-axis represents the various problems. The results suggest that majority of the respondents feel that the problems faced currently include aerosol production, lack of PPE, and infection control. One of the reasons for its statistical insignificance is because most of the respondents of the survey worked in Tamil Nadu.

Association between which state they belong to and the current problems was done using Chi-square test $(\mathrm{p}$-value $=$ $0.955)$ and is not statistically significant. Hence, the state and current problems faced are independent variables.

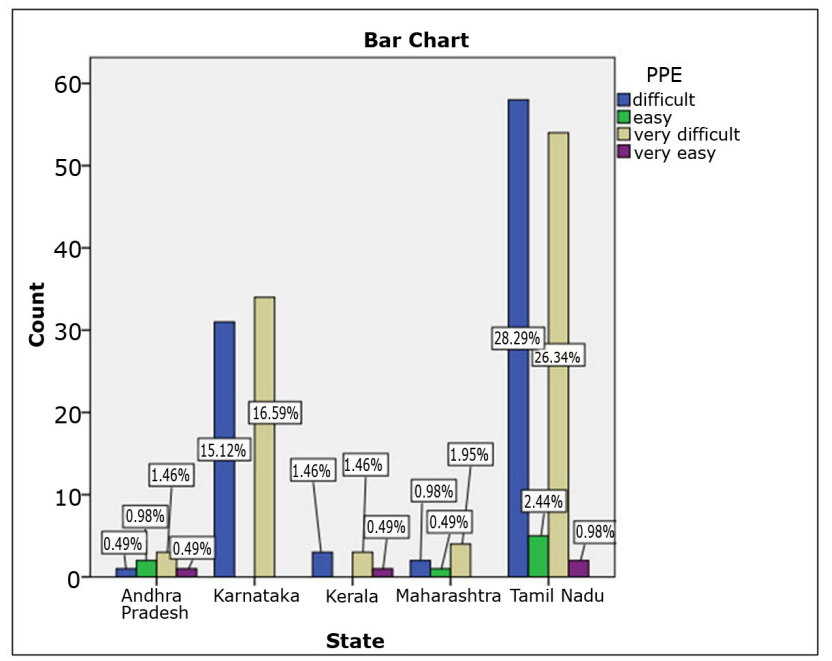

Graph 10: Bar graph representing the comparison between which state the professionals work in and the difficulty of obtaining PPE. X-axis represents the states and Y-axis represents the difficulty in obtaining PPE. The results suggest that most of the responses from Tamil Nadu feel it is "difficult" to obtain PPE. But, responses from the other states suggest that it is very difficult to obtain PPE. One of the reasons for its statistical insignificance is because most of the respondents of the survey worked in Tamil Nadu. 
Association between which state they belong to and the current problems was done using Chi-square test $(\mathrm{p}$-value $=$ 0.002 ) and is statistically significant.

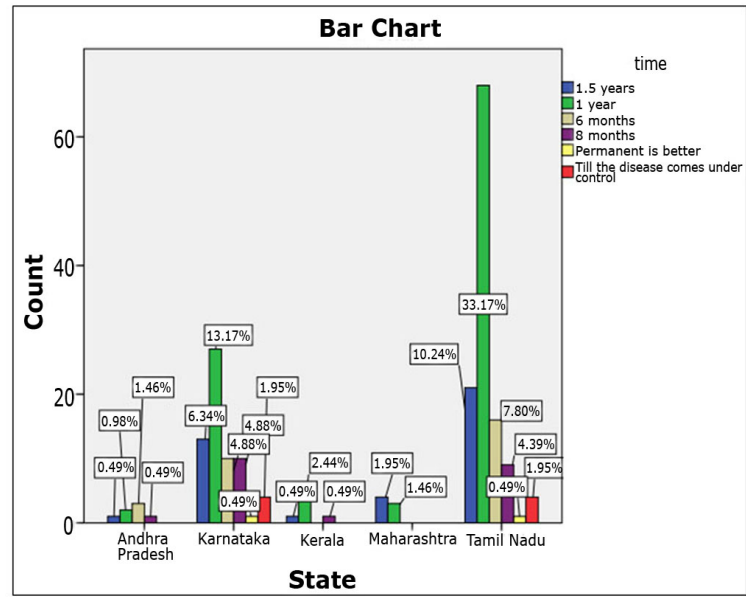

Graph 11: Bar graph representing the comparison between which state the professionals work in and the time duration for maintaining the changes in their workspace. $X$-axis represents the states and $\mathrm{Y}$-axis represents the time duration. From this graph, we can conclude that the majority of practitioners from Maharashtra alone felt that the changes must be maintained for about 1.5 years, whereas the majority from all other states feels that the changes can be maintained for 1 year. One of the reasons for its statistical insignificance is because most of the respondents of the survey worked in Tamil Nadu. Association between which state they belong to and the current problems was done using Chi-square test ( $p$-value $=0.417$ ) and is not statistically significant.

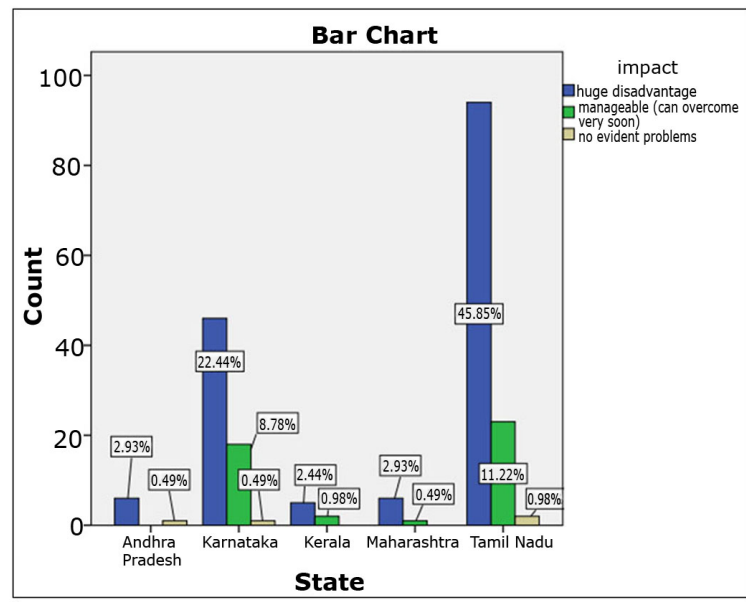

Graph 12: Bar graph representing the comparison between which state the professionals work in and the impact of the pandemic on dentistry. $\mathrm{X}$-axis represents the states and $\mathrm{Y}$-axis represents the degree of impact. The results from the graph suggest that the majority of the practitioners from all the states feel that $\mathrm{n}-\mathrm{CoV}$ was a huge disadvantage to dentistry. One of the reasons for its statistical insignificance is because most of the respondents of the survey worked in Tamilnadu.
Association between which state they belong to and the current problems was done using Chi-square test $(\mathrm{p}$-value $=$ 0.290 ) and is not statistically significant.

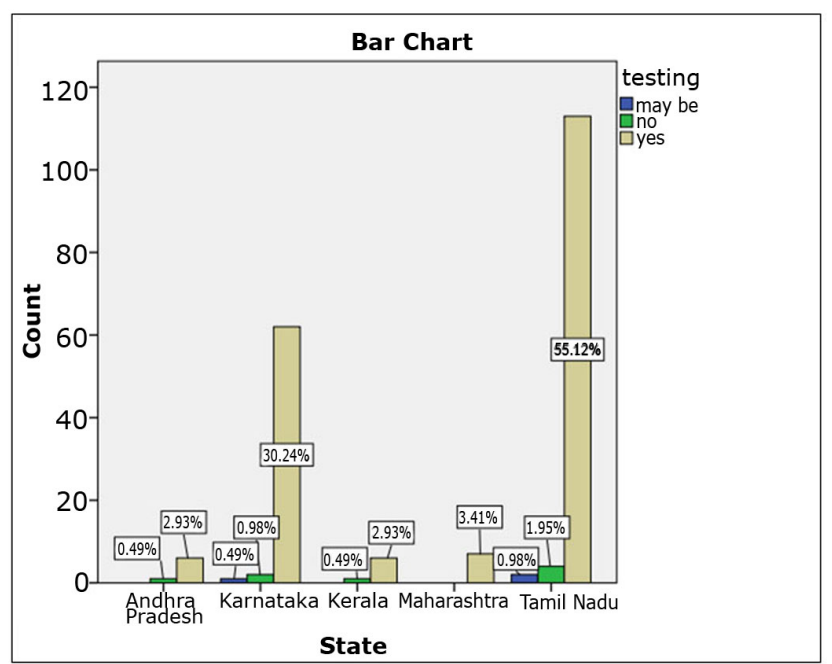

Graph 13: Bar graph representing the comparison between which state the professionals work in and the necessity for testing patients before dental procedures.

$\mathrm{X}$-axis represents the states and Y-axis represents the necessity for testing patients. One of the reasons for its statistical insignificance is because most of the respondents of the survey worked in Tamil Nadu.

Association between which state they belong to and the current problems was done using Chi-square test $(\mathrm{p}$-value $=$ 0.775 ) and is not statistically significant.

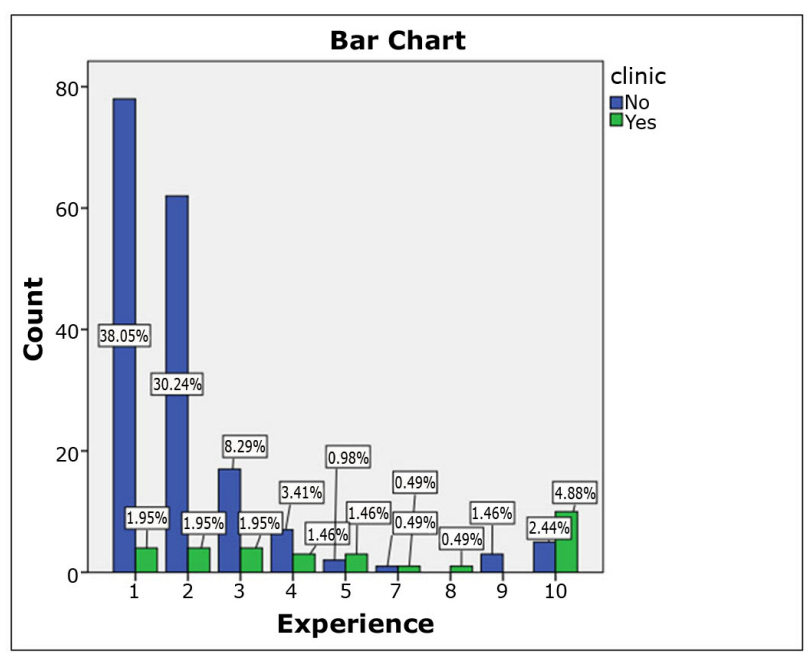

Graph 14: Bar graph representing the comparison between the number of years of experience and clinic ownership. $X$-axis represents the number of years of experience and Y-axis represents the status of clinic ownership. This graph suggests that the increased amount of dental work experience is directly proportional to whether the dentist is more likely to own a clinic. 
Association between the number of years of experience and clinic ownership was done using Chi-square test (p-value = 0.000 ) and is statistically significant.

The inference that can be made from this survey is that the most important parameter during such infectious outbreaks is infection control, aerosol reduction, and the correct use of PPE, especially in the dental profession.

One of the limitations of this survey is that the sample size could be larger. There can be slight differences in opinion among dentists from different states due to the variation in infection spread and degree of seriousness.

The main purpose of this survey is that it can be used in the future during similar outbreaks. Dental professionals also learn the different methods of infection control that other countries are following during this tough time of the pandemic. This will also spread awareness among dental professionals which will eventually lead to a safer and protected work environment.

\section{CONCLUSION}

COVID-19 is a highly infectious and contagious virus. It affects the respiratory tract and causes pneumonia. It is known to be present abundantly in the nasopharynx region which is close to the area where dentists perform their procedures. Due to their mode of transmission via aerosols, the dentists must take all the preventive measures to avoid the spread of infection. This puts the dentists at great risk of infection. From the results of the survey, it can be concluded that there are evident problems and difficulties in the future for dentists after the lockdown is relieved. The most important of which is infection control, aerosol reduction, and correct use of PPE.

\section{ACKNOWLEDGEMENTS}

The authors are thankful to Saveetha Dental College for providing a platform to express our knowledge. Authors acknowledge the immense help received from the scholars whose articles are cited and included in references to this manuscript. The authors are also grateful to authors / editors / publishers of all those articles, journals, and books from which the literature for this article has been reviewed and discussed.

\section{Conflict of Interest}

The authors declare no conflict of interest.

\section{Financial Support}

The authors declare no source of financial support.

\section{REFERENCES}

1. Girija ASS, Shankar EM, Larsson M. Could SARS-CoV-2-Induced Hyperinflammation Magnify the Severity of Coronavirus Disease (CoViD-19) Leading to Acute Respiratory Distress Syndrome? Front Immunol. 2020;11:1206.

2. Epidemiology Working Group for NCIP Epidemic Response, Chinese Center for Disease Control and Prevention. [The epidemiological characteristics of an outbreak of 2019 novel coronavirus diseases (COVID-19) in China]. Zhonghua Liu Xing Bing Xue Za Zhi. 2020 Feb 10;41(2):145-51.

3. Lu R, Zhao X, Li J, Niu P, Yang B, Wu H, et al. Genomic characterisation and epidemiology of 2019 novel coronavirus: implications for virus origins and receptor binding. Lancet. 2020;395(10224):565-74.

4. Chan JF-W, Yuan S, Kok K-H, To KK-W, Chu H, Yang J, et al. A familial cluster of pneumonia associated with the 2019 novel coronavirus indicating person-to-person transmission: a study of a family cluster. Lancet. 2020;395(10223):514-23.

5. Rothe C, Schunk M, Sothmann P, Bretzel G, Froeschl G, Wallrauch C, et al. Transmission of 2019-nCoV Infection from an Asymptomatic Contact in Germany. N Engl J Med. 2020;382(10):970-1.

6. Backer JA, Klinkenberg D, Wallinga J. Incubation period of 2019 novel coronavirus (2019-nCoV) infections among travellers from Wuhan, China, 20-28 January 2020. Euro Surveill [Internet]. 2020;25(5). Available from: http://dx.doi. org/10.2807/1560-7917.ES.2020.25.5.2000062

7. Jiang S, Xia S, Ying T, Lu L. A novel coronavirus (2019-nCoV) causing pneumonia-associated respiratory syndrome. Cell Mol Immunol. 2020;17(5):554.

8. Paramasivam A, Priyadharsini JV, Raghunandhakumar S, Elumalai P. A novel COVID-19 and its effects on cardiovascular disease. Hypertens Res [Internet]. 2020 Apr 30; Available from: http://dx.doi.org/10.1038/s41440-020-0461-x

9. Paramasivam A, Vijayashree Priyadharsini J, Raghunandhakumar S. N6-adenosine methylation (m6A): a promising new molecular target in hypertension and cardiovascular diseases. Hypertens Res. 2020 Feb;43(2):153-4.

10. Ashwatha Pratha A, Geetha RV. Awareness on Hepatitis-B vaccination among dental students-A Questionnaire Survey. Research Journal of Pharmacy and Technology. 2017 May 28;10(5):1360-2.

11. Fleischmann WR Jr. Viral Genetics. In: Baron S, editor. Medical Microbiology. Galveston (TX): University of Texas Medical Branch at Galveston; 2011.

12. Girija ASS, Vijayashree Priyadharsini J, Paramasivam A. Plasmid-encoded resistance to trimethoprim/sulfamethoxazole mediated by dfrA1, dfrA5, sul1 and sul2 among Acinetobacter baumannii isolated from urine samples of patients with severe urinary tract infection. J Glob Antimicrob Resist. 2019 Jun; 17:145-6.

13. Ashwin KS, Muralidharan NP. Vancomycin-resistant enterococcus (VRE) vs Methicillin-resistant Staphylococcus Aureus (MRSA). Indian J Med Microbiol. 2015 Feb;33 Suppl:166-7.

14. M MA, Geetha RV, Thangavelu L. Evaluation oEvaluation of anti-inflammatory action of Laurus nobilis-an in vitro studyf anti-inflammatory action of Laurus nobilis-an in vitro study. IJRPS. 2019 Apr 14;10(2):1209-13.

15. Ather A, Patel B, Ruparel NB, Diogenes A, Hargreaves KM. Coronavirus Disease 19 (COVID-19): Implications for Clinical Dental Care. J Endod. 2020 May;46(5):584-95.

16. Vijayashree Priyadharsini J, Smiline Girija AS, Paramasivam A. An insight into the emergence of Acinetobacter baumannii as an 
oro-dental pathogen and its drug resistance gene profile - An in silico approach. Heliyon. 2018 Dec;4(12):e01051.

17. Na A, Lin Y, Bin Z. Droplets and aerosols in dental clinics and prevention and control measures of infection. Zhonghua Kou Qiang Yi Xue Za Zhi. 2020 Feb 25;55(00):E004-E004.

18. Smiline A, Vijayashree JP, Paramasivam A. Molecular characterization of plasmid-encoded blaTEM, blaSHV and blaCTX-M among extended spectrum $\beta$-lactamases [ESBLs] producing Acinetobacter baumannii. Br J Biomed Sci. 2018 Oct;75(4):200-2.

19. Girija SA, Jayaseelan VP, Arumugam P. Prevalence of VIM- and GIM-producing Acinetobacter baumannii from patients with severe urinary tract infection. Acta Microbiol Immunol Hung. 2018 Dec 1;65(4):539-50.

20. Girija As S, Priyadharsini J V. CLSI based antibiogram profile and the detection of MDR and XDR strains of Acinetobacter baumannii isolated from urine samples. Med J Islam Repub Iran. 2019 Feb 8;33:3.

21. Sohaib Shahzan M, Smiline Girija AS, Vijayashree Priyadharsini J. A computational study targeting the mutated L321F of ERG11 gene in C. albicans, associated with fluconazole resistance with bioactive compounds from Acacianilotica. J Mycol Med. 2019 Dec;29(4):303-9.

22. Vijayashree Priyadharsini J, Smiline Girija AS, Paramasivam A. In silico analysis of virulence genes in an emerging dental pathogen A. baumannii and related species. Arch Oral Biol. 2018 Oct;94:93-8.

23. IDA. Indian Dental Association [Internet]. Available from: https://www.ida.org.in

24. ADA develops guidance on dental emergency, nonemergency care [Internet]. Available from: https://www.ada.org/en/publications/ada-news/2020-archive/march/ada-develops-guidance-ondental-emergency-nonemergency-care

25. Volgenant CMC, Persoon IF, de Ruijter RAG, de Soet JJH. Infection control in dental health care during and after the SARSCoV-2 outbreak. Oral Dis [Internet]. 2020 May 11; Available from: http://dx.doi.org/10.1111/odi.13408

26. Dentistry and coronavirus (COVID-19) - moral decision-making | British Dental Journal [Internet]. Available from: https:// www.nature.com/articles/s41415-020-1482-1

27. Emami E. COVID-19: Perspective of a Dean of Dentistry: JDR Clinical \& Translational Research [Internet]. 2020 May 13; Available from: https://journals.sagepub.com/doi/ full/10.1177/2380084420929284

28. Meng L, Hua F, Bian Z. Coronavirus Disease 2019 (COVID-19): Emerging and Future Challenges for Dental and Oral Medicine. J Dent Res. 2020 Mar 12;0022034520914246.

29. Huang S-M, Huang J-Y, Yu H-C, Su N-Y, Chang Y-C. Trends, demographics, and conditions of emergency dental visits in Taiwan 1997-2013: A nationwide population-based retrospective study. J Formos Med Assoc. 2019 Feb;118(2):582-7.

30. Dziedzic A. Special Care Dentistry and COVID-19 Outbreak: What Lesson Should We Learn? Dentistry Journal. 2020 Jun;8(2):46.

31. Dagli N, Dagli R. Increasing Unemployment among Indian Dental Graduates - High Time to Control Dental Manpower. J Int Oral Health. 2015 Mar; 7(3):i - ii.

32. Dickinson SK, Bebermeyer R, Ortolano K. Guidelines for Infection Control in Dental Health-Care Settings. American Dental Assistants Association. Department of Continuing Education; 2013.
33. Guidelines for infection control in dental health-care settings--2003. - PubMed - NCBI [Internet]. Available from: https://www.ncbi.nlm.nih.gov/pubmed/14685139

34. No need to panic over availability of PPE: Health ministry [Internet]. 2020. Available from: https://www.livemint.com/news/ india/no-need-to-panic-over-availability-of-ppe-health-ministry-11586432583257.html

35. Only month's stock of masks, suits in most hospitals, but Maharashtra says it's prepared | Mumbai News - Times of India [Internet]. Available from: https://timesofindia.indiatimes.com/city/ mumbai/only-months-stock-of-masks-suits-in-most-hospitalsbut-maharashtra-says-its-prepared/articleshow/74856292.cms

36. Management and Study of Hospital Infection-Chinese Journal of Nosoconmiology-2004,08 [Internet]. Available from: http:// en.cnki.com.cn/Article_en/CJFDTotal-ZHYY200408027.htm

37. Samaranayake LP, Peiris M. Severe acute respiratory syndrome and dentistry: A retrospective view. The Journal of the American Dental Association. 2004 Sep 1;135(9):1292-302.

38. Renuka S, Muralidharan NP. Comparison in benefits of herbal mouthwashes with chlorhexidine mouthwash: A review. Asian Journal of Pharmaceutical and Clinical Research. 2017 Feb $1 ; 10(2): 3-7$.

39. Shahana RY, Muralidharan NP. Efficacy of mouth rinse in maintaining oral health of patients attending orthodontic clinics. Intern Jour Contemp Microbiol. 2016;9(11):1991.

40. Vaishali M, Geetha RV. Antibacterial activity of Orange peel oil on Streptococcus mutans and Enterococcus - An In -vitro study. Research Journal of Pharmacy and Technology. 2018 Feb 28;11(2):513-4.

41. Marickar RF, Geetha RV, Neelakantan P. Efficacy of contemporary and novel Intracanal medicaments against enterococcus faecalis. J Clin Pediatr Dent. 2014 Autumn;39(1):47-50.

42. Marui VC, Souto MLS, Rovai ES, Romito GA, Chambrone L, Pannuti CM. Efficacy of preprocedural mouthrinses in the reduction of microorganisms in aerosol: A systematic review. J Am Dent Assoc. 2019 Dec;150(12):1015-26.e1.

43. Vandenberghe B, Jacobs R, Bosmans H. Modern dental imaging: a review of the current technology and clinical applications in dental practice. Eur Radiol. 2010 Nov;20(11):2637-55.

44. Diangelis AJ, Andreasen JO, Ebeleseder KA, Kenny DJ, Trope M, Sigurdsson A, et al. International Association of Dental Traumatology guidelines for the management of traumatic dental injuries: 1. Fractures and luxations of permanent teeth. Dent Traumatol. 2012 Feb;28(1):2-12.

45. World Health Organization. COVID-19: operational guidance for maintaining essential health services during an outbreak: interim guidance, 25 March 2020 [Internet]. World Health Organization; 2020 [cited 2020 Jun 5]. Report No.: WHO/2019-nCoV/ essential_health_services/2020.1. Available from: https://apps. who.int/iris/handle/10665/331561

46. COVID-19 Impact on Dental Practices - ADA Health Policy Institute [Internet]. Available from: https://www.ada.org/en/ science-research/health-policy-institute/covid-19-dentists-economic-impact

47. Coronavirus Disease 19 (COVID-19): Implications for Clinical Dental Care | American Association of Endodontists [Internet]. Available from: https://www.aae.org/specialty/clinical-resources/coronavirus-disease-19-covid-19-implications-for-clinicaldental-care/ 